\title{
Abrupt withdrawal of atenolol in patients with severe angina: comparison with the effects of treatment
}

Sir,

I have read the report by Walker et al (1985; 53: 276-82) on the results of a study on the effect of atenolol withdrawal in patients with chronic stable angina pectoris. As a result of their findings, they came to the rather dangerous conclusion that atenolol withdrawal can be expected to carry no appreciable risk of precipitating a coronary event in patients with little or no angina.

In 1979, Meinertz et al suggested that the abrupt discontinuation of any beta blocking agent should be expected to produce a withdrawal syndrome similar to that described for propranolol. ${ }^{1}$ The point at which rebound phenomena occur can be delayed for as long as 21 days after withdrawal ${ }^{2-4}$; the duration of the study performed by Walker $e t$ al was therefore too short to permit a conclusion that atenolol is devoid of this risk. Furthermore, in a different study, there was evidence of rebound withdrawal phenomena in two of 14 patients after substitution of atenolol by placebo. $^{5}$ Others have shown no difference between the beta blockers propranolol, oxprenolol, atenolol, and acebutolol in their propensity to cause a rebound increase of heart rate under conditions of increased sympathetic drive after withdrawal. ${ }^{6}$ The statement that atenolol has not yet been associated with a withdrawal syndrome is therefore incorrect.

Clearly there is a great deal of variability in the appearance of the beta blocker withdrawal syndrome and advice that treatment with any beta blocker should be withdrawn gradually, irrespective of the disease under treatment, still stands.

A Ashford,

May and Baker Ltd,

Rainham Road South,

Dagenham, Essex RM10 7XS.

\section{References}

1 Meinertz T, Just H, Kasper W, Kersting F, Breuing K-H. $\beta$-blocker withdrawal syndrome? Lancet 1979; i: 270.

2 Shand DG, Wood AJJ. Propranolol withdrawal syndrome-why? Circulation 1978; 58: 202-3.

3 Alderman EL, Coltart DJ, Wettach GE, Harrison DC. Coronary artery syndromes after sudden propranolol withdrawal. Ann Intern Med 1974; 81: 625-7.
4 Miller RR, Olson HG, Ezra AA, Mason DT. Propranolol withdrawal rebound phenomenon. $N$ Engl f Med 1975; 293: 416-8.

5 Kristensen Bent $\varnothing$. $\beta$-blocker withdrawal syndrome? Lancet 1979; i: 554.

6 Ross PJ, Lewis MJ, Sheridan DJ, Henderson AH. Adrenergic hypersensitivity after beta-blocker withdrawal. Br Heart $\mathcal{F}$ 1981; 45: 637-42.

This letter was shown to Dr Walker, who replies as follows:

Sir,

While we respect Dr Ashford's concern regarding the potential ill effects of abrupt beta blockade withdrawal we maintain that our results justify our conclusions. The suggestion of Meinertz et al was an extrapolation from one case (which concerned metoprolol), ${ }^{1}$ while the contention that rebound phenomena can occur as late as 21 days after withdrawal is based on just two patients, both of whom had developed unstable angina within 24 hours of propranolol withdrawal. ${ }^{2}$ Among 21 cases of the "propranolol withdrawal syndrome" in whom the timing of events was stated all but three occurred within seven days of withdrawal. ${ }^{2-5}$ Rebound adrenergic hypersensitivity-when it has been demonstrated $^{67}$-has always been maximal within seven days. Hence it cannot be confidently stated that these late events were rebound phenomena. While we accepted in our paper that our post-withdrawal period might ideally have been longer than 144 hours, it nevertheless included that time during which other workers have demonstrated rebound hypersensitivity under conditions of increased sympathetic drive.

Our statement that "atenolol has not as yet been associated with a withdrawal syndrome" is to our knowledge correct according to the definition which we and others have applied ${ }^{8}$ : that is, one inclusive of serious coronary events. The two (hypertensive) patients mentioned by Dr Ashford had no cardiac symptoms. Our data also showed that abrupt withdrawal of atenolol produces a gradual loss of beta blockade, which is why a gradual reduction in dosage is unnecessary.

We have attempted to avoid the rather anecdotal 
and speculative discussion which tends to surround the "beta blockade withdrawal syndrome", confining our conclusions to the specific agent and clinical setting tested. If it can ever be considered reasonable to withdraw a beta blocker then based on our data in patients with severe stable angina it should surely not be considered a "dangerous" practice to stop treatment with atenolol in patients who have mild or no symptoms?

P R Walker, Department of Cardiology, Bristol Royal Infirmary, Bristol BS2 8HW.

\section{References}

1 Meinertz T, Just H, Kasper W, Kersting F, Breuing
K-H. $\beta$-blocker withdrawal syndrome? Lancet 1979; i: 270.

2 Alderman EL, Coltart DJ, Wettach GE, Harrison DC. Coronary artery syndromes after sudden propranolol withdrawal. Ann Intern Med 1974; 81: 625-7.

3 Diaz RG, Somberg JC, Freeman E, Levitt B. Withdrawal of propranolol and myocardial infarction [Letter]. Lancet 1973; i: 1068.

4 Slome R. Withdrawal of propranolol and myocardial infarction [Letter]. Lancet 1973; i: 156.

5 Mizgala HF, Counsell J. Acute coronary syndromes following abrupt cessation of oral propranolol therapy. Can Med Assoc F 1976; 114: 1123-6.

6 Nattel S, Rangno RE, Loon GV. Mechanism of propranolol withdrawal phenomena. Circulation 1976; 59: 1158-64.

7 Ross PJ, Lewis MJ, Sheridan DJ, Henderson AH. Adrenergic hypersensitivity after beta-blocker withdrawal. Br Heart f 1981; 45: 637-42.

8 Shand DG, Wood AJJ. Propranolol withdrawal syndrome-why? Circulation 1978; 58: 202-3.

\section{Effect of timolol on changes in serum potassium concentration during acute myocardial infarction}

Sir,

Nordrehaug et al (1985; 53: 388-93) showed that the administration of timolol after myocardial infarction reduces the frequency of hypokalaemia during the first 24 hours after the infarct. For greater accuracy they should have used plasma rather than serum because there is erratic leakage from erythrocytes during coagulation.

Using insulin-induced hypoglycaemia (in healthy volunteers) as another model for acute stress, we have also observed that prior non-specific beta blockade with nadolol or propranolol prevents hypokalaemia. ${ }^{12}$ Since these effects of stress are mediated through a pronounced increase in plasma catecholamine concentrations it is pertinent to mention that adrenaline-induced influx of potassium into leucocytes in vitro is inhibited by the nonselective beta blocker, timolol and that these cells are probably a model for body cells as a whole. ${ }^{3}$ In addition, beta blockade in the hypoglycaemia model $^{1}$ reduces the magnitude of $(a)$ increase in serum free fatty acid concentrations by inhibiting lipolysis; $(b)$ the increase in various haemostatic variables like factor VIII related antigen; (c) platelet aggregation. These effects are related to the pathogenesis of myocardial infarction since they are all arrhythmogenic or prothrombotic. ${ }^{4-6}$ It is also important to determine whether selective blockade of beta ${ }_{1}$ receptors produces similar results since some of the above effects of catecholamines are thought to be mainly mediated by beta ${ }_{2}$ receptors.

\author{
D P Mikhailidis, \\ P Dandona, \\ D N Baron, \\ Department of Chemical Pathology and Human \\ Metabolism, \\ Royal Free Hospital and School of Medicine, \\ London NW3 2QG.
}

\section{References}

1 Mikhailidis DP, Barradas MA, Hutton RA, Jeremy JY, Sabur M, Dandona $P$. The effect of non-specific $\beta$-blockade on metabolic and haemostatic variables during hypoglycaemia. Diabetes Research 1985; 2: 127-34.

2 Mikhailidis DP, Dandona P. Adrenaline and potassium. Lancet 1984; i: 170.

3 Baron DN, Green RJ, Khan FA. Adrenaline and ion flux in isolated human leucocytes. Clin Sci 1985; 68: 517-21.

4 Tansey MJB, Opie LH. Relation between plasma free fatty acids and arrhythmias within the first twelve hours of acute myocardial infarction. Lancet 1983; ii: 419-22.

5 Jeremy JY, Mikhailidis DP, Dandona P. Simulating the diabetic environment modifies in vitro prostacyclin synthesis. Diabetes 1983; 32: 217-21.

6 Mikhailidis DP, Mikhailidis AM, Barradas MA, Dandona $P$. Effect of non-esterified fatty acids on the stability of prostacyclin activity. Metabolism 1983; 32: 717-21. 